\title{
Nephroprotective Effect of Echinodorus macrophyllus Micheli on Gentamicin-Induced Nephrotoxicity in Rats
}

\author{
Viviane Gomes Portella ${ }^{a}$ Gustavo Pereira Cosenza ${ }^{a}$ \\ Lúcio Ricardo Leite Diniz ${ }^{\mathrm{a}}$ Lílian Fernanda Pacheco ${ }^{\mathrm{a}} \mathrm{e}$ \\ Giovanni Dantas Cassali ${ }^{b}$ Marcelo Vidigal Caliari ${ }^{b}$ \\ Maria das Graças Lins Brandãoc Maria Aparecida Ribeiro Vieira ${ }^{\mathrm{a}, \mathrm{d}}$ \\ Departments of a Physiology and Biophysics and b Pathology, Institute of Biological Sciences, \\ cPharmacognosy Laboratory, Faculty of Pharmacy, and ${ }^{\mathrm{d}}$ National Institute of Science and Technology \\ in Nanobiopharmaceutics, Universidade Federal de Minas Gerais, Belo Horizonte, and eEscola Superior \\ de Educação Física de Goiás, Universidade Estadual de Goiás, Goiânia, Brazil
}

\section{Key Words}

Echinodorus macrophyllus Micheli • Alismataceae $\cdot$ Antidiuresis $\cdot$ Gentamicin $•$ Nephrotoxicity

\begin{abstract}
Background/Aims: Leaves of Echinodorus macrophyllus (EM), from the Alismataceae family, have been used in Brazilian folk medicine for their anti-inflammatory and diuretic properties. In this work, the diuretic and nephroprotective activities of crude extracts of EM were evaluated. Methods: Normal Wistar rats were given $0.9 \% \mathrm{NaCl}$ containing either EM $(10-300 \mathrm{mg} / \mathrm{kg})$, furosemide $(13 \mathrm{mg} / \mathrm{kg})$ or arginine vasopressin $(0.2 \mathrm{mg} / \mathrm{kg})$. Thereafter, the rats were individually housed in metabolic cages, and urine volume was measured every $30 \mathrm{~min}$ for a total of $3 \mathrm{~h}$. Acute kidney injury was induced by gentamicin (GM, $80 \mathrm{mg} \cdot \mathrm{kg}^{-1} \cdot$ day $^{-1}$, b.i.d., 5 days). Along with $\mathrm{GM}, 0.9 \% \mathrm{NaCl}$ (control) or EM ( $30 \mathrm{mg} / \mathrm{kg}$ ) was given to the rats by gavage. Results: EM produced a dose-dependent reduction in urine elimination. EM was effective in reversing all GM-induced alterations such as polyuria and glomerular filtration rate reduction. The GM-induced morphological alterations were not observed when EM was given concomitantly with GM. Conclusion: This study provides evidence that EM possesses nephroprotective effect which indicates that EM may have therapeutic applications in GM-induced acute kidney injury.
\end{abstract}

Copyright $\odot 2012$ S. Karger AG, Basel 


\section{Introduction}

Acute kidney injury (AKI) is defined as an abrupt reduction in kidney function. In critically ill patients, AKI is associated with increased morbidity (1-31\%) and increased mortality $(28-82 \%)$ [1]. This broad spectrum of outcome is due to the severity of illness, the population under study and nonstandardized criteria used to define AKI [2, 3]. Medications are responsible for nearly $20 \%$ of all cases of AKI in intensive care units [4]. Among the drugs that cause AKI are aminoglycoside antibiotics such as gentamicin (GM). GM-induced AKI is manifested clinically as nonoliguric renal failure, a slow rise in serum creatinine levels, a decrease in the glomerular filtration rate (GFR), acute tubular necrosis, aminoaciduria, hypokalemia and hypocalcemia [3,5-8].

In recent years, many compounds and therapeutic strategies have been utilized to prevent injury and to attenuate the progression of AKI. Likewise, medicinal herbs have been used to reduce or protect against nephrotoxicity. Ethanol extracts from the roots of Cassia auriculata Linn. showed a nephroprotective effect in cisplastin- and GM-induced renal injury [9]. Similarly, aqueous extracts of Phyllanthus amarus and green tea reduced GM-induced nephrotoxicity and oxidative damage in the rat kidney $[10,11]$. Echinodorus macrophyllus (EM) and Echinodorus grandiflorus from the Alismataceae family, popularly known in Brazil as 'chapéu de couro', are widely distributed in the tropical regions of Brazil. The leaves of both species have been used in folk medicine for their anti-inflammatory and diuretic properties [12]. Pinto et al. [13] have shown the immunosuppressive effects of EM, providing support for its use in the treatment of inflammatory diseases. However, to date, experimental studies on the diuretic activity of EM have not been performed. The objective of this study was to evaluate the diuretic properties of EM and to investigate its protective effect on GM-induced AKI in rats.

\section{Methods}

Obtaining EM and Method of Extraction

The leaves of EM were collected in the city of Belo Horizonte (Minas Gerais, Brazil). Voucher specimens (No. 28557) were identified and deposited at the herbarium of the Botanical Department (Institute of Biological Sciences, Universidade Federal de Minas Gerais, Belo Horizonte, Minas Gerais, Brazil).

The dried and pulverized leaves of EM $(1.2 \mathrm{~kg})$ were successively extracted by percolation with $80 \%$ ethanol, and then, the solvent was evaporated to dryness. The yield of the evaporated residue was $23 \%$ (mg of residue for each $100 \mathrm{~g}$ of the original dry leaves). The dried alcoholic extract from the leaves of EM was dissolved in $0.9 \% \mathrm{NaCl}$ solution and was used for further experimental assays.

\section{Animals}

Male Wistar rats (250-300 g) were obtained from the bioscience unit of our institution and were housed in standard conditions with free access to commercial chow and water. Animals were kept at a room temperature of $22^{\circ} \mathrm{C}$ with a light/dark cycle of $10 / 14 \mathrm{~h}$. All procedures described here were approved by the Institute's Animal Ethics Committee (protocol 177/2008).

\section{Effect of EM on Diuresis}

Rats were volume-expanded by gavage with $0.9 \% \mathrm{NaCl}$ ( $4 \%$ of body weight, isotonic expansion) containing EM $10 \mathrm{mg} / \mathrm{kg}(\mathrm{n}=9), 30 \mathrm{mg} / \mathrm{kg}(\mathrm{n}=5)$ and $300 \mathrm{mg} / \mathrm{kg}(\mathrm{n}=5)$, furose- 
mide $13 \mathrm{mg} / \mathrm{kg}(\mathrm{n}=6)$ or arginine vasopressin (AVP) $0.2 \mathrm{mg} / \mathrm{kg}(\mathrm{n}=5)$. The control group $(\mathrm{n}=9)$ received only $0.9 \% \mathrm{NaCl}$. After gavage, the rats were individually housed in metabolic cages, and the urine volume was measured every $30 \mathrm{~min}$ (for a total of $3 \mathrm{~h}$ ).

\section{Effect of EM on GM-Induced AKI}

Rats other than those used above (in the diuresis study) were individually housed in metabolic cages, and the urine volume was measured every $24 \mathrm{~h}$. After 3 days of adaptation to the metabolic cage conditions, the rats were divided into four groups (4 rats/group): all rats were injected subcutaneously (b.i.d.) with $0.5 \mathrm{ml}$ of $0.9 \% \mathrm{NaCl}$ containing or not (control group) GM ( $80 \mathrm{mg} \cdot \mathrm{kg}^{-1} \cdot \mathrm{day}^{-1}$; Gentotec, Chemitec, Brazil) (GM group). Afterward, the rats were orally given $0.9 \% \mathrm{NaCl}$ ( $4 \%$ body weight, gavage, b.i.d.) in the absence (control and GM groups) and presence of $30 \mathrm{mg} / \mathrm{kg}$ EM (EM and GM-EM groups) for 5 days. Protocol was always performed in the mornings. Urine production and water and chow intake were monitored every $24 \mathrm{~h}$. Both 24 -hour urine $(\sim 1 \mathrm{ml})$ and blood samples $(\sim 1 \mathrm{ml})$ were collected at the end of the treatment (on the 6th day in the morning). Blood was taken from the inferior vena cava. The rats were sacrificed, and their right kidneys were removed for histopathological examination.

\section{Analytical Procedures}

The GFR ( $\mathrm{ml} / 24 \mathrm{~h}$ ) was estimated by creatinine clearance. The plasma and urine creatinine concentrations were determined by spectrophotometry (Turner SP-830 plus; Barnstead, Dubuque, Iowa, USA) using a kit (Bioclin, Belo Horizonte, Minas Gerais, Brazil). The plasma and urine concentrations of $\mathrm{Na}^{+}$and $\mathrm{K}^{+}(\mathrm{mmol} / \mathrm{l})$ were measured in a flame photometer (Celm 180; Belo Horizonte, Minas Gerais, Brazil).

\section{Histomorphological Examination}

Samples of kidney tissue were fixed in buffered formalin embedded in paraffin. Thereafter, the samples were sectioned into 4 - $\mu \mathrm{m}$ thick slices and stained with hematoxylin and eosin.

\section{Statistical Analysis}

The data were analyzed using nonlinear regression and two-way ANOVA (fig. 1) and by one-way ANOVA followed by the Newman-Keuls test.

\section{Results}

\section{Effect of EM on Diuresis}

As shown in figure 1 , furosemide $(13 \mathrm{mg} / \mathrm{kg})$ produced a marked increase in urine volume (from $10.2 \pm 1.0 \mathrm{ml} / 180 \mathrm{~min}(\mathrm{n}=9)$ to $14.8 \pm 1.3 \mathrm{ml} / 180 \mathrm{~min}$ in the control group $(n=6)$ ). On the contrary, AVP induced a severe reduction in diuresis (from $10.2 \pm 1 \mathrm{ml} / 180$ $\min (\mathrm{n}=9)$ to $2.0 \pm 1.6 \mathrm{ml} / 180 \mathrm{~min}$ in the control group $(\mathrm{n}=5))$, as expected. The antidiuretic effect of EM was characterized by a dose-dependent reduction $(\mathrm{p}<0.05)$ in the urine output in normal rats (fig. 1). EM at the dose of $30 \mathrm{mg} / \mathrm{kg}$ produced a $30 \%$ decrease in the urine output at $180 \mathrm{~min}$ after administration. As this reduction did not represent the maximum effect of EM, $30 \mathrm{mg} / \mathrm{kg}$ was the dose of choice to perform the study on the GM-induced AKI.

\section{Effect of EM on GM-Induced AKI}

As shown in figure 2, treatment with GM (GM group) increased plasma creatinine levels from $0.28 \pm 0.04$ to $1.11 \pm 0.18 \mathrm{mg} / \mathrm{dl}(\mathrm{p}<0.05)$ (fig. $2 \mathrm{a})$. This was accompanied by a reduc- 
Fig. 1. Effect of increasing doses of EM on diuresis in rats in the absence (control group) or presence of EM. Furosemide and AVP were used as diuretic and antidiuretic controls, respectively.
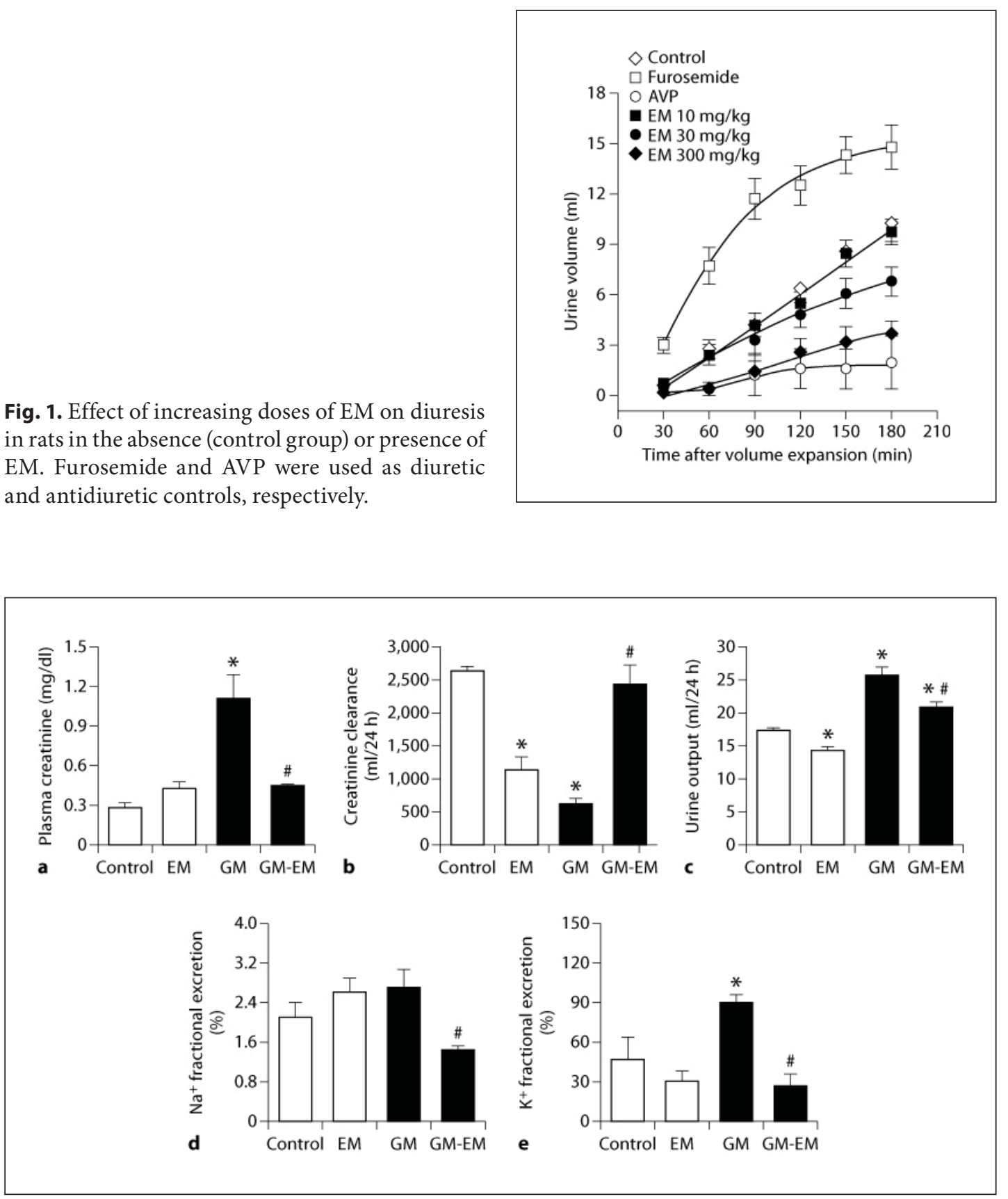

Fig. 2. Effect of EM on plasma creatinine levels (a), creatinine clearance (b), urine output (c), fractional excretion of $\mathrm{Na}^{+}(\mathbf{d})$ and $\mathrm{K}^{+}$(e) in rats with GM-induced AKI. One-way ANOVA followed by NewmanKeuls test, ${ }^{*} \mathrm{p}<0.05$ versus the control group and ${ }^{*} \mathrm{p}<0.05$ versus the GM group.

tion in the creatinine clearance from 2,643 \pm 146 to $616 \pm 174 \mathrm{ml} / 24 \mathrm{~h}(\mathrm{p}<0.05)$ (fig. $2 \mathrm{~b})$. In addition, the GM group showed a significant increase in urine output (from $17.3 \pm 1.2$ to $25.8 \pm 3.4 \mathrm{ml} / 24 \mathrm{~h}, \mathrm{p}<0.05$ ) and in the fractional excretion of $\mathrm{K}^{+}$(from $46.7 \pm 17.0$ to 90.0 $\pm 5.9 \%, \mathrm{p}<0.05$ ), as shown in figure $2 \mathrm{c}$, e. No significant change in the excretion of $\mathrm{Na}^{+}$was detected in the GM group when compared to the control group ( $0.9 \% \mathrm{NaCl}$ alone) (fig. $2 \mathrm{~d})$. In the rats that were given EM (GM-EM group), most GM-induced renal alterations were not 

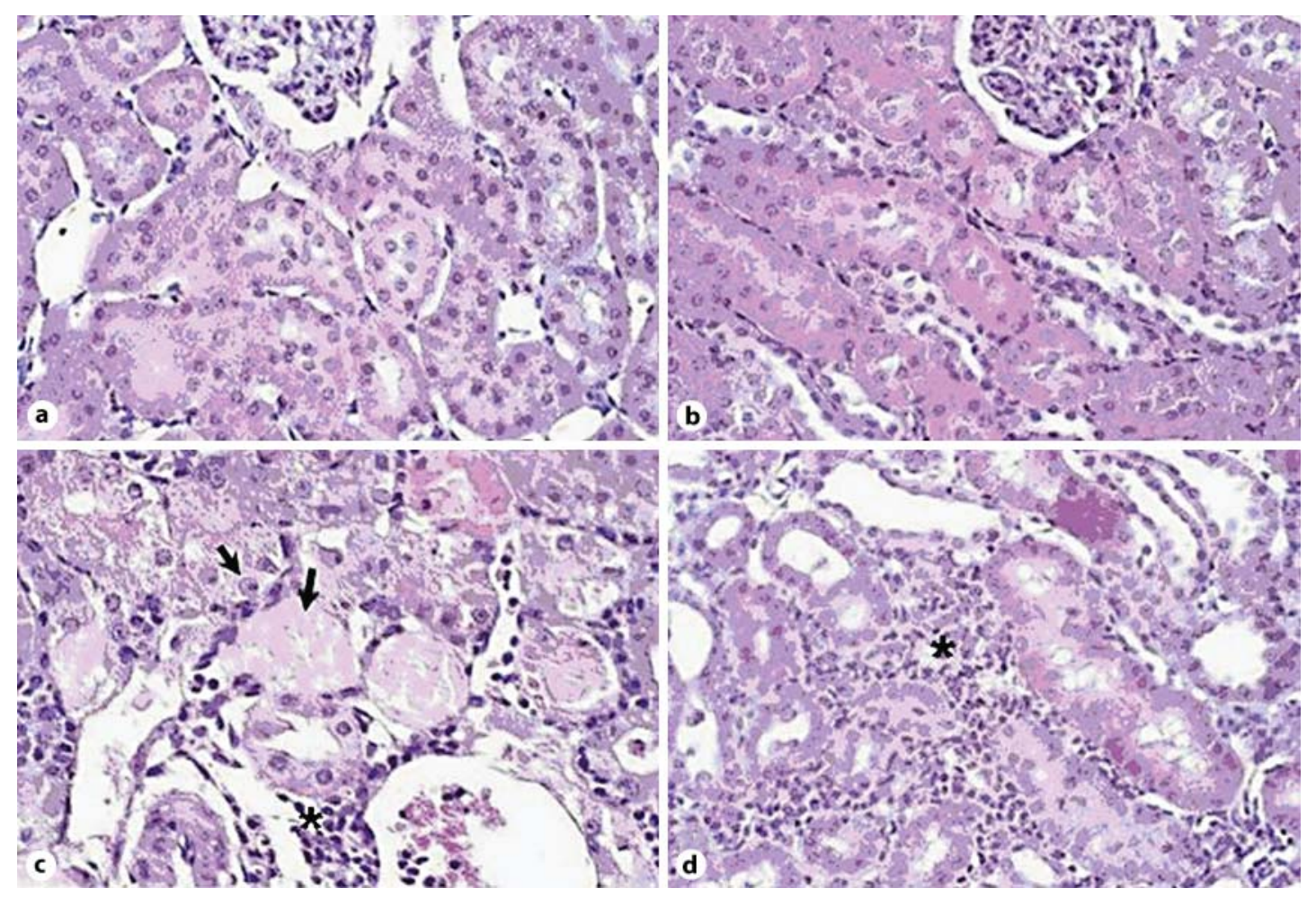

Fig. 3. Effect of EM on the morphology of the rat kidneys with GM-induced AKI. a Control kidney showing a normal histological architecture of glomeruli and tubules. $\mathbf{b}$ Section of a kidney of a normal rat that received EM (EM group). EM did not produce any detectable alteration in the renal structure of the normal rat. c Section of a kidney from a GM-treated rat (GM group) showing renal alterations compatible with acute tubular necrosis: cytoplasmic vacuolization, pyknotic nucleus (arrows) and inflammatory infiltrate (asterisks). d Section of a kidney from a GM-induced AKI in a rat treated with EM (GM-EM group). Most changes observed in $\mathbf{c}$ are not observed in $\mathbf{d}$ (hematoxylin and eosin-stained; magnification, $40 \times)$.

observed. Furthermore, EM (GM-EM group) also promoted a reduction in the fractional excretion of $\mathrm{Na}^{+}$when compared to the GM group (fig. 2d).

In figure 3, the morphological traits of the kidneys of the GM-treated rats with or without simultaneous administration of EM were compared. GM-induced acute tubular necrosis was evidenced by the presence of both cellular vacuolization and pyknotic nuclei (fig. 3c). Most signs of acute tubular necrosis were not observed in the group that was simultaneously treated with EM (fig. 3d). A slight increase in the infiltration of inflammatory cells was still observed in the EM-treated kidney.

\section{Discussion}

We have shown that EM induces a dose-dependent antidiuretic effect in rats and exhibits a significant nephroprotective effect in the GM-induced AKI model.

In contrast to the claimed diuretic effect of EM in Brazilian folk medicine, we observed that EM promotes an antidiuretic activity. A reduction in the GFR may be responsible, at least in part, for the antidiuretic effect observed in normal rats treated with EM (fig. 2b). The 
magnitude of volemia and the protocol design might explain the discrepancies between our findings and the effects that are expected according to the traditional medicine. EM-induced antidiuresis may be clinically important given the necessity of novel compounds for the treatment of diseases such as pituitary diabetes insipidus and nephrogenic diabetes insipidus [14]. AVP and desmopressin are commonly used to treat these diseases, but they produce many side effects [15]. In addition, it has been reported that diuretics augment the AKI induced by nephrotoxic drugs, such as GM, when both are administered together $[16,17]$. Therefore, it is worthwhile to investigate the combined effects of drugs with antidiuretic activities, such as EM with GM, on nephrotoxicity.

Some therapeutic agents have been used to attenuate injury and prevent the progression of GM-induced AKI, including antioxidants and extracts of medicinal plants $[6,9,18]$. The extract of Andrographis paniculata $(200 \mathrm{mg} / \mathrm{kg})$ reduced serum creatinine levels after 10 days of oral treatment [19]. Similarly, single oral administration of the extract of Phyllanthus amarus $(100-400 \mathrm{mg} / \mathrm{kg} / \mathrm{day})$ for 14 days reduced serum creatinine levels and attenuated GMinduced tubulonephrosis [10]. In agreement with previous reports [3, 8], we have observed that GM increased the urine output and urinary excretion of $\mathrm{K}^{+}$and plasma creatinine levels and reduced GFR. Importantly, coadministration of EM inhibited all renal function alterations promoted by GM (fig. 2). Furthermore, EM reduced the damage observed in renal tubules.

Many studies have suggested that free radicals are important mediators in GM-induced renal damage $[18,20]$. In addition, several other researchers have attributed the nephroprotective effect of medicinal plants to the antioxidant compounds present in these herbs. The renoprotective activity of Visicum articulatum Burm and Ligusticum wallichii is attributed to tetramethylpyrazine and oleanolic acid, both with antioxidant compounds [7,21]. Similarly, quercetin, a polyphenolic flavonoid widely found in edible plants, possesses antioxidant properties and protects rat kidneys from GM-induced nephrotoxicity [22, 23].

In conclusion, using a murine model, this study provides evidence that EM possesses both antidiuretic activity and nephroprotective effect which indicates that EM may have therapeutic applications in GM-induced AKI. Additional studies are required to further confirm our results and to evaluate the applicability of this model to human individuals.

\section{Acknowledgements}

This work was supported by grants from Coordenadoria de Aperfeiçoamento de Pessoal de Nível Superior (CAPES), Conselho Nacional de Desenvolvimento Científico e Tecnológico (CNPq) and Fundação de Amparo à Pesquisa do Estado de Minas Gerais (FAPEMIG, APQ-02637-10).

\section{Disclosure Statement}

The authors declare that they have no conflicts of interest. 


\section{References}

$\checkmark 1$ Dennen P, Douglas IS, Anderson R: Acute kidney injury in the intensive care unit: an update and primer for the intensivist. Crit Care Med 2010;38:261-275.

2 Ricci Z, Cruz DN, Ronco C: Classification and staging of acute kidney injury: beyond the RIFLE and AKIN criteria. Nat Rev Nephrol 2011;7:201-208.

-3 Oliveira JF, Silva CA, Barbieri CD, et al: Prevalence and risk factors for aminoglycoside nephrotoxicity in intensive care units. Antimicrob Agents Chemother 2009;53:2887-2891.

-4 Uchino S, Kellum JA, Bellomo R, et al: Acute renal failure in critically ill patients: a multinational, multicenter study. JAMA 2005;294:813-818.

5 Yaklin KM: Acute kidney injury: an overview of pathophysiology and treatments. Nephrol Nurs J 2011;38:13-18.

-6 Ali BH: Agents ameliorating or augmenting experimental gentamicin nephrotoxicity: some recent research. Food Chem Toxicol 2003;41:1447-1452.

-7 Juan $\mathrm{SH}$, Chen $\mathrm{CH}, \mathrm{Hsu} \mathrm{YH}$, et al: Tetramethylpyrazine protects rat renal tubular cell apoptosis induced by gentamicin. Nephrol Dial Transplant 2007;22:732-739.

$>8$ Selby NM, Shaw S, Woodier N, et al: Gentamicin-associated acute kidney injury. QJM 2009;102: 873-880.

-9 Annie S, Rajagopal PL, Malini S: Effect of Cassia auriculata Linn. root extract on cisplatin and gentamicin-induced renal injury. Phytomedicine 2005;12:555-560.

-10 Adeneye AA, Benebo AS: Protective effect of the aqueous leaf and seed extract of Phyllanthus amarus on gentamicin and acetaminophen-induced nephrotoxic rats. J Ethnopharmacol 2008;118:318-323.

-11 Khan SA, Priyamvada S, Farooq N, et al: Protective effect of green tea extract on gentamicin-induced nephrotoxicity and oxidative damage in rat kidney. Pharmacol Res 2009;59:254-262.

-12 da Silva CJ, Bastos JK, Takahashi CS: Evaluation of the genotoxic and cytotoxic effects of crude extracts of Cordia ecalyculata and Echinodorus grandiflorus. J Ethnopharmacol 2010;127:445-450.

-13 Pinto AC, Rego GC, Siqueira AM, et al: Immunosuppressive effects of Echinodorus macrophyllus aqueous extract. J Ethnopharmacol 2007;111:435-439.

-14 Ratnasooriya WD, Jayakody JR, Nadarajah T: Antidiuretic activity of aqueous bark extract of Sri Lankan Ficus racemosa in rats. Acta Biol Hung 2003;54:357-363.

-15 Vande Walle J, Stockner M, Raes A, et al: Desmopressin 30 years in clinical use: a safety review. Curr Drug Saf 2007;2:232-238.

-16 Ali BH, Al-Qarawi AA, Mahmoud OH, et al: Influence of spironolactone treatment on gentamicininduced nephrotoxicity in rats. Basic Clin Pharmacol Toxicol 2004;95:20-23.

-17 Nakahama H, Fukuhara Y, Orita Y, et al: Furosemide accelerates gentamicin accumulation in cultured renal cells (LLC-PK1 cells). Nephron 1989;53:138-141.

-18 Lopez-Novoa JM, Quiros Y, Vicente L, et al: New insights into the mechanism of aminoglycoside nephrotoxicity: an integrative point of view. Kidney Int 2011;79:33-45.

- 19 Pedraza-Chaverri J, Maldonado PD, Medina-Campos ON, et al: Garlic ameliorates gentamicin nephrotoxicity: relation to antioxidant enzymes. Free Radic Biol Med 2000;29:602-611.

20 Singh P, Srivastava MM, Khemani LD: Renoprotective effects of Andrographis paniculata (Burm. f.) Nees in rats. Upsala J Med Sci 2009;114:136-139.

-21 Patil CR, Jadhav RB, Sigh PK, et al: Protective effect of oleanolic acid on gentamicin induced nephrotoxicity in rats. Phytother Res 2010;24:33-37.

-22 Abdel-Raheem IT, Abdel-Ghany AA: Protective effect of quercetin against gentamicin-induced nephrotoxicity in rats. Biol Pharm Bull 2009;32:61-67.

23 Dajas F, Rivera-Megret F, Blasina F, et al: Neuroprotection by flavonoids. Braz J Med Biol Res 2003; 36:1613-1620. 